\title{
Regimes e Políticas Cambiais: Uma Visão Geral
}

\author{
Exchange rate regimes and policies: a general view
}

W. MAX CORDEN*,**

RESUMO: Este artigo apresenta os princípios econômicos gerais da política cambial e fornece uma visão geral dos quatro casos de países que foram incluídos nesta edição especial da revista: México, Brasil, Argentina e Venezuela. São discutidos três principais regimes monetários - o regime fixo, mas ajustável (FBAR), a taxa firmemente fixa e o regime de taxa flutuante. Ao mesmo tempo, o artigo distingue entre duas abordagens principais da política cambial: a abordagem da âncora nominal e a abordagem de metas reais. $\mathrm{O}$ autor identifica os custos e benefícios da implementação desses vários regimes cambiais através das diferentes fases da estabilização macroeconômica e do ajuste estrutural. Embora a dolarização tenha se tornado cada vez mais discutida como outra opção de política monetária na América Latina, o autor observa que essa tendência ainda é incipiente demais para ser abordada neste artigo.

PALAVRAS-CHAVE: Política cambial; regime cambial; liberalização.

ABSTRACT: This article lays out the general economic principles of exchange rate policy and provides an overview of the four country cases that have been included in this special edition of the journal: Mexico, Brazil, Argentina, and Venezuela. Three main currency regimes are discussed - the fixed but adjustable regime (FBAR), the firmly fixed rate, and the floating rate regime. At the same time, the article distinguishes between two main approaches to exchange rate policy: the nominal anchor approach and the real targets approach. The author identifies the costs and benefits of implementing these various exchange rate regimes through the different phases of macroeconomic stabilization and structural adjustment. Although dollarization has become increasingly discussed as another monetary policy option in Latin America, the author notes that this trend is still too incipient to address at any length in this article.

KEYWORDS: Exchange rate regime; exchange rate policy; liberalization.

JEL Classification: F31; F32.

\footnotetext{
* Chung Ju Yung Distinguished Professor of International Economics and Business at the Johns Hopkins University, Paul H. Nitze School of Advanced International Studies - SAIS, Washington/DC, United States. E-mail: m.corden@unimelb.edu.au.

** Tradução de Maria Cristina Godoy.
} 
Os países latino-americanos são dignos de nota tanto pela variedade de regimes cambiais que escolheram ou foram forçados a adotar quanto pelas inúmeras variações em suas políticas cambiais. Tais características serão ressaltadas nos próximos capítulos, embora as discussões abarquem muito mais do que as políticas cambiais e as crises monetárias. Neste capítulo, o objetivo é delinear alguns princípios gerais e fornecer uma visão geral dos regimes e políticas cambiais dos quatro países incluídos como estudos de caso neste volume: México, Brasil, Argentina e Venezuela.

Distinguem-se aqui três tipos principais de regimes cambiais: o regime fixo, mas ajustável (doravante denominado FBAR, de acordo com as iniciais em inglês), o regime de taxa rigidamente fixada e o regime de taxa flutuante. Embora raramente se observem versões puras desses tipos - a realidade é mais complexa e intrincada -, a classificação é útil.

Atualmente, tanto o Brasil como o México têm regimes de taxa flutuante, com algum nível de monitoramento. Em ambos os países, crises monetárias levaram ao fim seus sistemas de FBARs e precipitaram a mudança para regimes de taxa flutuante. A Argentina tem (mais ou menos) um regime de taxa rigidamente fixada, que se seguiu a uma inflação explosiva que terminou em hiperinflação. O caótico regime cambial precedente pode ser descrito melhor como flexível, quase flutuante, com episódios intermitentes de FBAR; no entanto, descrever sucintamente a história macroeconômica da Argentina antes de 1991 é quase impossível. A Venezuela, por fim, tem um FBAR.

Antes de discutir os três tipos de regimes, devemos distinguir dois métodos de política cambial: o método da âncora nominal e o das metas reais. Cada um tem suas vantagens e desvantagens. O conflito entre eles e a dificuldade de fazer uma transição do primeiro para o segundo têm dominado as histórias cambiais dos quatro países e, a bem dizer, as de muitos outros países da América Latina. As questões envolvidas aqui são diferentes das que se originam da alta mobilidade do capital internacional e da especulação cambial, que também são discutidas adiante.

\section{O MÉTODO DA ÂNCORA NOMINAL E O MÉTODO DAS METAS REAIS}

A ideia básica do método da âncora nominal é de que a taxa de câmbio nominal deve ancorar a taxa de inflação do país. O valor da moeda é atrelado à moeda de um outro país que tenha um registro de inflação baixa bem estabelecido e digno de crédito. ${ }^{1}$ No caso da América Latina, essa moeda é obviamente o dólar. Para

\footnotetext{
${ }^{1}$ Sobre o método da âncora nominal, ver Michael Bruno, " High Inflation and the Nominal Anchors of an Open Economy”, Essays in International Finance 183 (International Finance Section, Princeton University, 1991); W. Max Corden, "Exchange Rate Policy in Developing Countries”, in Richard C. Barth e Chong-Hu y Wong, eds., Approaches to Exchange Rate Policy: Choices for Developing and Transition Economies (International Monetary Fund, 1994), pp. 65-89; W. Max Corden, Economic Policy, Exchange Rates, and the International System (Universiry of Chicago Press, 1994); e Jilleen R.
} 
esse método funcionar, o atrelamento a uma taxa fixa do dólar significa que a inflação baixa é, na verdade, importada dos Estados Unidos. Mas isso funciona? Deixando de lado, no momento, as especulações sobre a moeda, a eficácia desse método baseia-se em dois requisitos: é necessário que haja disciplina monetária e é necessário que haja credibilidade no mercado de trabalho.

Se a taxa de câmbio estiver fixa, mas a base monetária continuar a se expandir, as reservas cambiais declinarão, o que não pode prosseguir indefinidamente. Em particular o método da âncora nominal significa que os déficits fiscais não podem ser financiados pela criação de moeda, a não ser na medida em que um aumento na demanda por moeda permita alguma expansão da base monetária sem um declínio nas reservas cambiais. Assim, o método da âncora nominal entrará em colapso se a disciplina fiscal não for mantida. Em muitos países latino-americanos, inclusive três dos quatro discutidos neste livro, a obtenção da disciplina fiscal foi o problema central; a incapacidade de manter tal disciplina foi a principal razão para o colapso das políticas cambiais com âncora nominal. A exceção foi o México, onde a crise de 1994 não foi causada por falta de disciplina fiscal, mas teve origem num boom do setor privado.

Além disso, se a taxa de inflação dos preços dos bens negociáveis tiver de ser reduzida para a taxa do país que serve de âncora, os salários nominais também deverão ser ajustados de acordo. Se os salários crescerem a uma velocidade mais alta, os salários reais - ao menos nos setores de bens negociáveis (os setores importador-competidor e exportador) - aumentarão, e se crescerem mais rápido do que o aumento da produtividade, ocorrerão aumento do desemprego e perdas de resultado. Isso também não pode prosseguir indefinidamente. Se não se espera que a taxa da inflação de preços caia porque não se espera que o regime da taxa cambial fixa possa ser mantido, então a inflação de salários também não declinará, ou pelo menos não o suficiente. Como é provável que os preços de artigos não negociáveis aumentem juntamente com os salários, haverá valorização real contínua. Assim, a política da âncora nominal precisa ter credibilidade no mercado de trabalho. Essa credibilidade depende não apenas do atrelamento da taxa de câmbio, mas também da credibilidade da política monetária. É possível realmente alcançar uma disciplina de política monetária - que em geral depende em grande medida de uma disciplina fisca1?

O método da âncora nominal na verdade pode não envolver a fixação da taxa de câmbio. Pode haver crawling peg. Nesse caso, a velocidade em que a moeda é paulatinamente desvalorizada é predeterminada num valor menor do que a taxa inicial de inflação, de modo que a taxa de inflação dos produtos negociáveis decline gradualmente. Se os salários e os preços dos produtos não negociáveis caírem numa velocidade mais lenta, haverá constante valorização real. Ao mesmo tempo,

Westbrook e Thomas D. Willett, "Exchange Rates as Nominal Anchors: An Overview of the Issues", in Richard J. Sweeney, Clas Wihlnorg, e T. D. Willett, eds., Exchange-Rate Policies for Emerging Market Economies (Boulder: Westview Press, 1999), pp. 83-112. 
desde que a disciplina monetária seja obtida, a taxa de inflação realmente declinará. A vantagem desse método é que ele pode desempenhar um papel crucial na redução da inflação. Pode desempenhar, como aconteceu muitas vezes, um papelchave nos programas de estabilização em países com inflação alta, como Argentina, Brasil e México. A desvantagem é que os custos do fracasso são altos - perda de reservas cambiais resultante da falta de disciplina monetária e fiscal, além de desemprego e perda de resultados decorrentes da valorização real.

A premissa básica do método das metas reais é que a taxa de câmbio nominal varia em função de alvos reais, tais como alcançar a taxa de câmbio real exigida para um alto nível de emprego ou para a melhoria das contas correntes. Fica implícita nesse método a ideia de que uma desvalorização nominal também acarretará uma desvalorização real. ${ }^{2}$

Se houver algum tipo de choque adverso - digamos, um declínio nas relações de troca ou uma redução na entrada de capitais-, pode ser necessária um a desvalorização real, que levará a uma maior competitividade, para melhorar as contas correntes. $\mathrm{Na}$ falta de um a desvalorização real, somente uma redução nos gastos, que acarrete uma recessão e, portanto, um declínio suficiente nas importações, pode alcançar a melhoria desejada. Da mesma forma, quando um país sofre uma valorização real contínua em virtude de seguir o método da âncora nominal, mas apresenta uma credibilidade insuficiente no mercado de trabalho, a mudança para o método das metas reais torna-se quase inevitável. A taxa de câmbio nominal terá de ser depreciada para produzir a desejada taxa de câmbio real e assim restaurar a competitividade. É um procedimento padrão o uso da taxa de câmbio nominal como um instrumento de política, quando é necessária uma melhoria nas contas correntes; durante muitos anos esteve no centro dos programas de estabilização da balança de pagamentos do Fundo Monetário Internacional (FMI). Os gastos totais também precisam declinar, é claro, portanto, a recomendação ou condição habitual do FMI tem sido a contração fiscal combinada com a desvalorização.

\section{OS TRÊS REGIMES: FIXO MAS AJUSTÁVEL, RIGIDAMENTE FIXO E FLUTUANTE}

A história latino-americana está atulhada com os cadáveres de regimes cambiais fixos, mas ajustáveis. Nesse regime, a taxa de câmbio é inicialmente fixada, e há um firme atrelamento a ela, mas existe sempre a possibilidade de alterações. $\mathrm{O}$ país ainda tem uma política monetária independente. No entanto, as mudanças em geral são feitas com relutância. O período de taxa fixa é impulsionado pelo método da âncora nominal, enquanto a mudança para uma nova taxa mais desvalorizada - geralmente como resultado de uma desvalorização - é impulsionada pelo método das metas reais.

\footnotetext{
2 'Sobre o método das metas reais, ver Corden, "Exchange Rate Policy in Developing Countries".
} 
Um país com uma taxa de inflação alta pode fixar a taxa de câmbio como parte de um programa de estabilização destinado a reduzir a inflação, mas em geral a taxa não é realmente fixa; em vez disso, introduz-se uma crawling peg com um índice predeterminado de desvalorização. Em algum momento haverá uma desvalorização (maior do que a variação da banda), seja para compensar a valorização real ocorrida, seja em resposta a algum tipo de choque adverso - talvez um declínio nas relações de troca ou na entrada de capitais. Em outras palavras, os "fundamentos" exigem uma desvalorização. Também é possível que a contração necessária da política monetária não tenha sido feita durante o período da taxa fixa, provocando uma queda nas reservas cambiais. Isso exige uma melhoria das contas correntes e, novamente, uma desvalorização real se faz necessária. O problema é que a taxa fixa não pode ser totalmente digna de crédito, pois sempre existe a possibilidade de desvalorização. Se ficar evidente que os fundamentos provavelmente exigem uma desvalorização real, a corrida à moeda poderá precipitar uma crise cambial.

Quando há alta mobilidade do capital internacional e quando os controles cambiais (se houver) não são totalmente eficazes, o mercado cambial antecipará a desvalorização exigida pelos fundamentos - isto é, pelo método das metas reais. Isso pode acontecer mesmo se houver controles eficazes, mas inversões no ritmo dos pagamentos por importações e exportações também desempenham um papel. A especulação, assim, provocará uma crise mesmo antes que as reservas cambiais se tenham esgotado, e possivelmente antes mesmo que a temida mudança política ou o declínio nas relações de troca tenha efetivamente ocorrido. A crise pode ser desencadeada por acontecimentos muito pequenos ou mesmo por observações pouco hábeis de um Ministro da Fazenda ou de um presidente do Banco Central. Apesar disso, ela simplesmente antecipa o inevitável, ou seja, a mudança para o método das metas reais. Experiências tanto na América Latina quanto no Leste da Ásia também mostraram que tal crise pode levar ao ajuste excessivo da taxa de câmbio - uma depreciação abrupta seguida de uma certa recuperação da taxa.

Em geral, os governos tentam evitar a depreciação aumentando as taxas de juros, mas efeitos internos adversos colocam limites ao aumento agudo e prolongado das taxas de juros que pode ser necessário para segurar a taxa. $\mathrm{O}$ mercado pode perceber que há limites para o aumento das taxas de juros, e assim a confiança na taxa fixa não se sustentará. O Ministro da fazenda, então, se sente obrigado a apoiar a política de altas taxas de juros com afirmações de que não haverá desvalorização. Finalmente, as autoridades são obrigadas a desvalorizar a taxa ou a permitir que ela flutue. Quando a desvalorização finalmente ocorre, o governo está desacreditado. Os governos, e sobretudo os ministros da Fazenda, não gostam dessas crises.

A desvalorização tem de ser suficiente para assegurar ao mercado de que não haverá outras desvalorizações. No início, o Banco Central venderá dólares em troca de moeda corrente para manter a taxa. A seguir, ele comprará de volta os dólares para recompor as reservas. Nesse processo - vender dólares a preço baixo e comprá-los a preço mais alto-, ele terá perdas, às vezes muito grandes, em benefício dos especuladores. Essa é a história de uma crise cambial típica. 
É compreensível a relutância dos governos em desvalorizar quando é evidente que pode ser necessária uma desvalorização, como discutido adiante nos estudos de caso deste livro. Em resumo, existe preocupação de que as expectativas inflacionárias sejam reavivadas e de que os salários nominais aumentem rapidamente para compensar os efeitos reais de uma desvalorização. Além disso, uma desvalorização teria efeitos adversos em vários setores: consumidores de produtos importados, produtores internos que dependem de insumos importados, além de bancos e outros com dívidas em dólar. Quanto mais frágil for o sistema bancário, maior a relutância em desvalorizar. Finalmente, quando a desvalorização acontece, ou quando a taxa é obrigada a flutuar, o governo que construiu seu programa de estabilização sobre a segurança de uma taxa fixa ou de uma variação de banda previamente anunciada perde credibilidade. Esta síndrome do ajuste relutante da taxa de câmbio é, na verdade, o problema central dos FBARs quando há margem para especulação contra a moeda, e em particular quando o país está significativamente integrado ao mercado mundial de capitais. ${ }^{3}$

O regime de taxa rigidamente fixada pode oferecer uma maneira de evitar tais problemas. Em 1991, a Argentina instituiu currency board baseado em seu Plano de Conversibilidade; a adoção desse regime é agora advogada por muitos países. O currency board é uma das versões de um regime de taxa rigidamente fixada. ${ }^{4} \mathrm{~A}$ ideia por trás do currency board é de que a taxa de câmbio fixa tem total credibilidade porque há um atrelamento firme em relação a ela, apoiado por uma lei que garante que a política monetária será totalmente determinada pelo nível das reservas cambiais. Isso significa que os déficits fiscais não podem ser monetarizados e que o Banco Central não pode agir como emprestador de última instância ao sistema bancário. É feito um compromisso segundo o qual todo o dinheiro interno com alto poder pode ser trocado por moeda estrangeira (por dólares, no caso da Argentina). Tal regime precisa ter credibilidade tanto no mercado de trabalho como no mercado cambial. Com isso, os vários tipos de crises cambiais que perturbaram ou destruíram tantos FBARs seriam evitados - é o que se espera - bem como a contínua valorização real. Deve-se observar, no entanto, que essas expectativas não se realizaram totalmente na Argentina.

Apesar disso, um regime totalmente fixo tem duas grandes vantagens. Em primeiro lugar, ele garante completa estabilidade cambial, pelo menos com relação ao país "hegemônico" (nesse caso, os Estados Unidos), o que é de grande conveniência para os movimentos do comércio e do capital. Em segundo lugar, ele garante que a taxa de câmbio seja realmente uma âncora nominal que disciplina a

\footnotetext{
${ }^{3}$ As desvantagens e a insustentabilidade dos FBARs foram mais claramente expostas por Maurice Obstfeld e Kennet Rogott, “The Mirage of Fixed Exchange Rates”, Journal of Economic Perspectives, vol. 9 (1995), pp. 73-96. Ver também Mihael Mussa e outros, Exchange Rate Regimes in an Increasingly Integrated World Economy (International Monetary Fund, 2000)

${ }^{4}$ Sobre " currency boards, ver John Williamson, What Role for Currency Boards? Policy Analyses in International Economics 40 (Institute for International Economics, 1996)
} 
política monetária e põe em xeque as expectativas inflacionárias, mantendo assim a taxa de inflação praticamente igual à dos Estados Unidos. É um método apropriado para dois tipos de países: (1) aqueles com economias muito pequenas e abertas, nas quais não é provável que o ajuste nominal da taxa de câmbio leve a verdadeiras mudanças na taxa de câmbio por um período significativo; e (2) aqueles que têm uma longa história de inflação alta causada pela falta de disciplina monetária. Evidentemente, a Argentina é um ótimo exemplo deste último grupo.

A desvantagem desse regime é que o uso do método de metas reais está descartado. Sem poder recorrer à desvalorização, no caso de um choque adverso - seja um declínio nas relações de troca, um fluxo de saída de capital, ou um abrupto declínio no fluxo de entrada - a base monetária deve poder declinar (e as taxas de juros devem poder subir), para que a demanda interna caia e as contas correntes melhorem. Ocorrerá uma recessão, a menos que os salários nominais internos e os preços dos bens não negociáveis declinem suficientemente. Qualquer melhoria na competitividade que se fizer necessária poderá ser obtida apenas através da flexibilidade dos salários e preços internos. A flexibilidade do mercado de trabalho, que é um problema especial para Argentina, é crucial para o sucesso do regime de taxa cambial rigidamente fixada.

A Argentina tem uma história de inflação alta e instável, culminando numa hiperinflação em 1989. Os efeitos adversos ficaram evidentes para qualquer cidadão. Há uma máxima muito conhecida de que as coisas têm de ficar muito más antes que o povo de um país esteja pronto para reformas radicais. Na Argentina, as coisas ficaram realmente muito mal. Isso explica, sem sombra de dúvida, a boa-vontade do governo e, agora, de todos os principais partidos políticos, em aceitar as restrições impostas pelo sistema de currency board, que terminou dramaticamente com a inflação argentina. Mas um outro fator foi tão importante quanto esse no estabelecimento e na sobrevivência do sistema. A inflação argentina tinha sido causada, essencialmente, pela monetarização dos déficits fiscais. Uma das pré-condições para o estabelecimento e a sobrevivência do sistema era a reforma fiscal radical. Essas reformas estão incompletas, como mostra o capítulo 5, mas aquelas orquestradas pelo ministro da Economia Domingo Cavallo foram realmente radicais no início. Até um certo ponto, os déficits fiscais podem ser financiados por empréstimos tomados junto aos mercados de capital domésticos e mundiais, em vez de se apoiarem na monetarização, mas há limites para o financiamento da dívida. O mercado vai perceber esses limites e prever que o sistema de currency board entrará em colapso se houver previsão de perda de controle fiscal.

O sistema de currency board não pode ser completamente digno de crédito, porque pode ser encerrado. Além disso, as expectativas levam tempo para se ajustar. Embora a inflação argentina tenha declinado dramaticamente em relação aos níveis de 1991, esse declínio foi acompanhado de uma valorização real considerável, com os salários aumentando mais rápido do que o desejável para evitar o crescente desemprego. Além disso, houve especulação contra o peso, provocando aumentos internos nas taxas de juros bem acima das taxas dos EUA. Na verdade, o sistema do currency board poderia ser visto como uma forma extrema de FBAR, 
com os ajustes sendo altamente improváveis, mas não completamente descartados. Apenas se a Argentina fosse completamente dolarizada - isto é, usasse o dólar norteamericano como sua moeda e unidade de conta - haveria um sistema de taxa de câmbio rigidamente fixada. Haveria uma única e completa conversão de todos os pesos em dólares, o que acabaria com a especulação. Não poderia haver especulação contra um peso inexistente.

O regime puro de taxa flutuante é aquele que não tem, literalmente, nenhuma política cambial. Uma política monetária que não é restringida por nenhum atrelamento à taxa de câmbio desempenha o mesmo papel que a política cambial desempenha no FBAR ou no regime de taxa rigidamente fixada. Uma meta monetária, ou uma meta de inflação explícita, se digna de crédito e aplicada com consistência, pode ancorar a taxa de inflação, embora possa ser uma âncora nominal menos eficaz do que um atrelamento crível e bem transparente à taxa de câmbio. Assim, o método da âncora nominal pode ser executado por meio da política monetária. O Brasil, particularmente, vem seguindo desde 1999 uma política monetária explícita de metas de inflação A meta é feita para ser transparente, propiciando orientação temporária para a redução gradual da inflação (a partir de $8 \%$ ) durante três anos, e uma âncora firme depois disso. A política monetária também pode ser dirigida para uma meta real, tal como influenciar o emprego ou, aliás, a taxa de câmbio.

$\mathrm{Na}$ prática, os regimes de taxa flutuante raramente são puros. Há quase sempre algum monitoramento da taxa de câmbio, na forma de uma intervenção direta no mercado pelo Banco Central, destinada a evitar movimentos extremos e volatilidade a curto prazo. O ponto-chave é que não há um atrelamento a uma taxa específica, e que a taxa de câmbio pode ser volátil em resposta a mudanças de expectativas. Foi o medo ou o desagrado em relação a essa volatilidade que tornou impopulares as taxas flutuantes.

Tanto o Brasil quanto o México têm agora regimes de taxa flutuante, mas isso não foi realmente uma escolha. Eles resultaram de crises que não deixaram outra alternativa. Se as políticas fiscal e monetária, porém, são bastante estáveis e críveis, e se não há grandes choques, as taxas flutuantes não geram inevitavelmente grande instabilidade. Além disso, as taxas dólar-ien-euro, que flutuam, não têm sido estáveis de modo algum; tem havido movimentos substanciais de longo prazo, para cima e para baixo, na paridade dólar-ien, considerados extremos e indesejáveis por muitos economistas.

Uma variação do regime de taxa flutuante é o regime de paridade flexível. Nesse caso, o Banco Central determina uma taxa, ou possivelmente uma banda para a taxa, mas está sempre pronto a alterá-la. Não há um atrelamento forte. Desse modo, as crises e outros problemas criados pelo FBAR podem ser evitados. De modo geral, esse tem sido o método chileno nos últimos anos. ${ }^{5}$ Esse regime

\footnotetext{
${ }^{5}$ Ver Rudiger Dornhusch e Sebastian Edwards, “Exchange Rate Policy and Trade Strategy”, in Barry P. Bosworth, Rudiger Dornbusch, e Raúl Labán, eds., The Chilean economy: Policy Lessons and Challenges (Brookings, 1994), pp. 81-115.
} 
evita a volatilidade a curto prazo e é um meio-termo razoável entre os regimes FBAR e flutuante. Está próximo de um regime flutuante monitorado, porque em ambos os casos o Banco Central intervém no mercado, mas não há um atrelamento forte a um a taxa de câmbio específica. Um aperfeiçoamento adicional e comum foi o de permitir que a taxa de câmbio flutue dentro de uma banda (ou zona-alvo) em torno da paridade, havendo, nos limites da banda, algum tipo de compromisso com a intervenção. Essa variação representa uma nova adaptação entre uma paridade flexível, ou mesmo um FBAR, e um regime de taxa flutuante.

\section{OS ESTUDOS DE CASO}

Os próximos artigos desta edição tratam de quatro países. O currency board da Argentina já foi mencionado várias vezes anteriormente. Ele conseguiu reduzir dramaticamente a taxa de inflação, mas o desemprego está sendo alto porque o merca do de trabalho não foi suficientemente flexível. Houve várias recessões profundas desde 1991. Já a Venezuela, é um caso clássico de repetidas tentativas de regimes de taxa de câmbio (mais ou menos) fixa mas ajustável, destinadas a reduzir a inflação, inicialmente acompanhadas da disciplina fiscal adequada, mas seguidas de uma deterioração dessa disciplina e, finalmente, de um colapso do regime como consequência de uma crise cambial. Isso é o que Javier Corrales chama de síndrome "ax-relax-collapse" [corta-relaxa-quebra, num efeito de aliteração em inglês]. A inflação então se acelera novamente e recomeça todo o processo, com uma aplicação do método da âncora nominal. Detalhes completos dessa triste história podem ser encontrados no artigo de Javier Corrales.

Para os fins deste livro, a história do Brasil começa com a hiperinflação de 1993. O Plano Real foi introduzido em 1994, e no seu centro estava a utilização da taxa de câmbio como âncora nominal. A inflação foi reduzida de modo bastante rápido, e a política monetária era apertada, como indicavam as altas taxas de juros reais. Inicialmente, houve um breve ajuste fiscal, mas o déficit fiscal aumentou de novo, permanecendo alto. As altas taxas de juros sobre a dívida pública contribuíram para esse aumento. Tudo isso está descrito em maiores detalhes no artigo de Eliana Cardoso. Os déficits fiscais foram financiados com a emissão de dívida para o público, não para o Banco Central. Na verdade, o déficit fiscal foi financiado tanto pela poupança privada interna quanto pela poupança externa, esta última refletindo-se num crescente déficit em conta corrente. As altas taxas de juros, bem como a restauração da confiança na economia brasileira, atraíram as entradas de capital externo. Como costuma acontecer sempre que o método da âncora nominal foi usado para reduzir a inflação, houve uma constante valorização real.

A história brasileira difere da nossa descrição anterior de um típico processo de FBAR num ponto importante: embora os déficits fiscais tenham continuado, eles não foram monetarizados, o que não permitiu que a inflação revivesse. Ao contrário, os déficits foram parcialmente financiados pela tomada de empréstimos externos. Desse modo, o problema não era uma volta da inflação ou uma incapacidade 
de fazer a inflação cair, mas, ao contrário, o perigo de que a entrada de capital externo acabasse. $\mathrm{Na}$ verdade, a entrada de capitais continuou apenas em razão das altas taxas de juros reais, que na realidade aumentaram o déficit fiscal. Desenvolveu-se uma expectativa de desvalorização, em virtude da clara percepção de que os déficits fiscais crescentes (ou mesmo estáveis) não poderiam ser continuamente financiados, o que levou então à crise cambial já conhecida. As razões para a relutância em desvalorizar diante dessa crise aparentemente inevitável foram as já conhecidas, listadas anteriormente na discussão sobre a síndrome do ajuste relutante da taxa de câmbio. Em face da história recente do Brasil de inflação extrema, e da longa história de indexação, havia um medo legítimo de que qualquer desvalorização reacendesse as expectativas inflacionárias e levasse a aumentos compensatórios nos salários nominais. Isso não apenas poderia transformar em nova derrota a difícil vitória contra a inflação, mas qualquer desvalorização inicial real resultante de uma desvalorização nominal poderia rapidamente ser corroída. Deve-se notar aqui que, como aconteceu após a crise de 1999, os temores sobre os efeitos adversos de uma forte depreciação da taxa de câmbio não encontraram justificativa nos fatos. A inflação não reacendeu.

O que a economia exigia era uma severa redução no déficit fiscal primário (sem os juros) combinada com uma desvalorização real. Se o déficit tivesse sido severamente reduzido, as expectativas de desvalorização - e a crise que forçou a desvalorização - poderiam ter sido evitadas. Se não houvesse desvalorização, no entanto, poderia ter havido uma recessão. A desvalorização era claramente desejável. Com base no método das metas reais - na verdade, na análise ortodoxa do balanço interno e externo - fazia-se necessária uma desvalorização real para tornar o país mais competitivo, evitando assim, ou moderando, uma recessão que, caso contrário, poderia ter resultado da contração fiscal.

Admite-se que essa visão poderia ser modificada pela seguinte consideração: a restauração da confiança resultante da contração fiscal (se esta pudesse ser obtida) reduziria as taxas de juros reais, estimulando, portanto, uma expansão compensatória na demanda do setor privado. Desse modo, talvez não fosse necessária uma desvalorização para evitar a recessão. Pode-se argumentar, porém, que tal expansão compensatória na demanda do setor privado poderia abreviar ou mesmo neutralizar a melhoria tão necessária nas contas correntes que a contração fiscal teria provocado.

O que distingue a crise mexicana que se iniciou em 1994 da última crise brasileira e de crises anteriores em muitos outros países latino-americanos, inclusive a Argentina e o próprio México, é o fato de ela ter se iniciado a partir de um boom no setor privado, e não de um déficit fiscal excessivo. É verdade que a crise foi causada em parte pela inepta reestruturação de grande parte da dívida pública: de uma dívida em pesos para uma dívida de curto prazo em dólares (através da emissão dos agora notórios tesobonos). No entanto, embora a reestruturação tenha provocado um perigo imediato de inadimplência do setor público em 1995, ela não foi o centro do problema. A escolha feita pelo México do seu regime cambial em 1994 foi muito mais relevante para essa questão. 
A história principal do México é simples. A partir de meados de 1992, houve, por várias razões, um boom na entrada de capitais privados. Isso ajudou a financiar um boom nos gastos do setor privado, mais no consumo do que no investimento, o que levou a uma valorização real contínua e significativa. O México tinha um FBAR, que havia reduzido radicalmente, e com sucesso, a taxa de inflação do pico de mais de $100 \%$ ao ano que havia atingido em 1988. A valorização real ocorreu porque a taxa de inflação permaneceu significativamente acima da taxa dos EUA. É importante observar que se a taxa de câmbio tivesse flutuado durante o boom, ainda assim teria havido valorização real, mas induzida pela valorização da taxa de câmbio nominal. Assim, o regime cambial não pode ser considerado responsável pela valorização real, uma vez que foi o resultado inevitável da alta entrada de capitais.

Também inevitavelmente, mas por razões internas particulares ao México, além de aumentos nas taxas de juros nos Estados Unidos, a entrada de capitais começou a diminuir em 1994, transformando-se por fim numa saída de capitais. Dado que o boom dos gastos internos não poderia mais ser financiado, só havia três alternativas de política, antes que a crise cambial no final de 1994 tivesse tirado das autoridades a capacidade de escolha.

A taxa de câmbio poderia ter permanecido fixa enquanto se permitia que a demanda interna declinasse, em parte como resultado da contração monetária, e assim as taxas de juros teriam sido maiores, em razão da não-esterilização dos efeitos monetários da queda nas reservas cambiais. Nesse caso poderia ter ocorrido uma recessão, possivelmente grave. Além de ser politicamente pouco atraente, essa opção teria prejudicado severamente um sistema bancário que já era frágil.

Além disso, a taxa de câmbio poderia ter sido desvalorizada ou poderia ser levada a flutuar, ao mesmo tempo que ocorreria alguma contração de demanda; isso teria melhorado as contas correntes e, depois de um certo tempo, evitado a recessão. Mas esse caminho não foi o escolhido, em virtude de todas as razões já enumeradas acima sobre os ajustes relutantes da taxa de câmbio, e que explicam por que os governos evitam a desvalorização quando estão sob um regime de FBAR.

A terceira alternativa foi a escolhida, no mínimo por não haver outras. A taxa de câmbio nominal foi mantida e não foi permitido à demanda interna se contrair. Desse modo, evitou-se uma recessão, pelo menos até a crise. As reservas cambiais declinaram paulatinamente, e quando o mercado (nesse caso, acima de tudo, o próprio povo mexicano) percebeu a grande probabilidade de desvalorização ou depreciação, o processo culminou numa crise cambial, que levou a um regime de taxa flutuante e a um ajuste excessivo da depreciação.

A conclusão nesse caso é que, dado que a entrada maciça de capitais pode declinar e depois se transformar em saída, a escolha do regime cambial se torna crucial. Se a taxa tivesse flutuado no início de 1994, bem antes da crise, o arrefecimento na entrada de capitais teria causado muita instabilidade, mas a depreciação poderia ter ocorrido antes e talvez de modo não tão abrupto. E o que é mais importante, desde que a depreciação acabasse sendo real e não apenas nominal - uma condição importante - a inevitável recessão poderia ter sido apenas moderada. 


\section{DUAS CAUSAS DA CRISE: DÉFICITS FISCAIS E INSTABILIDADE DO MERCADO DE CAPITAIS}

Em muitos casos o centro do problema foi a política fiscal - mais especificamente, a incapacidade ou a falta de vontade do governo, por razões políticas, de controlar a política fiscal e de evitar déficits excessivos. Isso é claramente confirmado pelo estudo dos casos brasileiro e venezuelano neste livro, e também foi verdade para o caso da Argentina antes de 1991. Na verdade, um estudo patrocinado pelo Banco Mundial sobre as experiências de 18 países em desenvolvimento antes, durante e depois da crise da dívida dos anos 80 concluiu que, com apenas uma exceção, a falta de disciplina fiscal foi a causa principal da crise. ${ }^{6}$ Esse estudo cobriu o período de meados dos anos 60 até o início dos anos 90. Embora todos os países ali estudados tivessem FBARs, não é difícil mostrar que uma política fiscal super-expansionista teria também criado grandes problemas tanto para os regimes de currency board como para os regimes de taxa flutuante. A única exceção foi o Chile, onde a crise de 1982 foi resultado de um boom do setor privado financiado pela entrada de capitais, que se encerrou abruptamente em virtude da valorização real e dos choques externos adversos. Evidentemente, também a crise mexicana de 1994 não esteve associada a um problema fiscal significativo.

Há, na verdade, dois canais através dos quais os déficits orçamentários podem criar crises monetárias. Primeiramente, os déficits podem ser financiados pela monetarização, isto é, pela venda de títulos do governo ao Banco Central. Desse modo, a base monetária cresce de modo constante e a inflação aparece. Não há disciplina monetária porque não há disciplina fiscal. Essencialmente, o déficit fiscal é financiado pelo imposto inflacionário sobre os detentores de saldos monetários e de títulos a juros fixos. Com um FBAR, a expansão monetária leva à valorização real, à diminuição das reservas cambiais e à inevitável crise cambial. Como observado acima, a crise pode vir a ocorrer antes que o estoque das reservas se esgote, à medida que os residentes do país e os operadores do mercado cambial interna e externamente prevejam a inevitável desvalorização. Vívidos exemplos desse tipo de acontecimento podem ser encontrados na história da Argentina durante o período coberto pelo estudo do Banco Mundial acima referido.

Em segundo lugar, os déficits fiscais podem ser financiados pela venda de títulos no mercado. Nesse caso, existe a possibilidade de uma crise não inflacionária. Uma mudança da monetarização para o financiamento de títulos - tomando emprestado no mercado de capitais doméstico e internacional - pode acarretar um declínio acentuado na inflação, com todas as consequências bem-vindas que isso produz. Haverá menor valorização real e menor declínio nas reservas cambiais. $\mathrm{O}$ FBAR pode então ser sustentado por muito tempo. Tal mudança, da monetarização para o financiamento de títulos, aconteceu no Brasil durante o período descrito no

\footnotetext{
${ }^{6}$ Ver Ian M. D. Little, Richard N. Cooper, W. Max Corden, e Sarath Rajapatirana, eds., Boom, Crisis, and Adjustment: The Macroeconomic Experience of Developing Countries (Oxford University Press and The World Bank, 1993).
} 
artigo de Eliana Cardoso e também na Rússia em 1995, em ambos os casos levando a uma diminuição drástica na velocidade da inflação. Mas apenas postergou o dia do acerto de contas. Com um déficit fiscal alto em relação ao crescimento da economia, inevitavelmente as taxas de juros irão subir, a conta corrente irá deteriorar-se, as altas taxas de juros irão piorar o déficit fiscal mesmo com um déficit primário (sem juros) bastante constante, e a dívida interna e externa irá crescer. O custo do serviço da dívida em relação às exportações e ao PIB irá crescer de modo constante. Desse modo, os mercados acabarão por prever que a situação é insustentável. Haverá previsões de uma necessidade de reestruturação do serviço da dívida, possivelmente até mesmo por inadimplência, ou, o que é mais provável, uma volta à monetarização. À medida que se interrompe a entrada de capitais para financiamento do déficit, a depreciação se torna inevitável. Assim o FBAR entra em colapso. Um regime de currency board não pode também, é claro, sobreviver a tal situação.

Se o déficit fiscal não puder ser mantido dentro dos limites determinados pela disponibilidade de financiamento não-inflacionário, a taxas razoáveis de juros, a monetarização será inevitável, bem como a inflação persistente e a taxa de câmbio flutuante. Se os déficits altos continuarem, a crise subsequente tomará a forma não diretamente de uma crise cambial, mas de uma crise de ruptura social e econômica resultante da inflação, e que terminará em hiperinflação, como ocorreu na Argentina e no Brasil a partir de 1989.

Os perigos dos déficits fiscais excessivos têm sido amplamente reconhecidos na América Latina, sobretudo na Argentina, no Brasil e no México. A luta para conter tais déficits continua, mas é provável que as lições tenham sido aprendidas e que as futuras crises oriundas da política fiscal ou das perdas das empresas paraestatais se tornem mais raras. Os próximos capítulos mostram que o Brasil conquistou importantes vitórias cm 1999. Talvez o problema fiscal deixe mesmo de dominar a história econômica latino-americana. No mundo da alta mobilidade de capitais, no entanto, com mercados de capital liberalizados ou difíceis de controlar, um outro tipo de crise - chamada de a crise do século XXI - pode vir a se tornar cada vez mais importante. Um dos precursores foi a crise chilena de 1982. Ela resultou da instabilidade dos mercados privados de capital. Nesse tipo de crise, não apenas os emprestadores mas também os tomadores de empréstimos estão no setor privado. A primeira dessas crises, com exceção da chilena, precursora, foi a crise mexicana de 1994, descrita em profundidade no artigo de Timothy Kessler. O caso mais típico foi a crise asiática de 1997-98, que afetou os países do Leste da Ásia, que tinham longas e notáveis histórias de disciplina fiscal e inflação relativamente baixa.

Os mercados de capital passam por estágios de euforia, seguidos por outros de pânico. Primeiro, há uma entrada maciça de capitais num país, depois subitamente ela se interrompe e se transforma em saída. No primeiro estágio, as taxas de câmbio reais se valorizam e no segundo, elas são obrigadas a se depreciar. Embora o FBAR seja compatível com a valorização real em virtude do aumento nos preços internos, um fracasso ou relutância em depreciar não é compatível com a depreciação real necessária, em razão da rigidez descendente dos salários nominais e dos preços dos bens não negociáveis. No primeiro estágio há um déficit em conta corrente, e no segundo estágio há necessidade de um superávit nas contas correntes. A 
queda nos gastos em bens e serviços internos ("absorção") que é necessária para induzir a mudança de um déficit em conta corrente para um superávit é automaticamente provocada pelo pânico do setor privado, geralmente causando uma profunda recessão. A inevitabilidade da depreciação - causada pela necessidade de depreciação real para moderar a recessão e melhorar a conta corrente - leva a corridas especulativas sobre a moeda. Isso aconteceu no Chile em 1982, no México em 1994 e nos países do Leste da Ásia em 1997. Assim, os países foram forçados a abandonar seus FBARs.

As questões políticas aqui são amplas. Poderia a eufórica entrada de capitais, num primeiro momento, ser moderada por controles do capital, por evitar-se dar garantias governamentais implícitas aos tomadores ("risco moral") e por fornecer mais informações aos mercados? E poderia a súbita e assustadora interrupção de entradas de capital e a demanda pelo reembolso de dívidas ser moderada ou evitada, também com controles, com melhor informação e com suporte financeiro temporário adequado do Fundo Monetário Internacional? E mais, poderiam os emprestadores privados ser solicitados ou encorajados a reestruturar seus empréstimos em épocas de crise? Tudo isso e muito mais é o tema de uma vasta literatura recente provocada pela crise asiática e preocupada com a pretensiosamente denominada "reforma da arquitetura financeira internacional". ${ }^{7} \mathrm{O}$ ponto importante a ser ressaltado aqui é que tal moderação dos ciclos do fluxo internacional de capitais é desejável, qualquer que seja o regime cambial.

Essas questões estão além do âmbito desta análise, mas precisam ser salientadas. Elas também se aplicam, até certo ponto, a situações em que a causa da entrada inicial de capitais não foi uma demanda por fundos originária do setor privado, mas sim um déficit fiscal. Se refletirmos sobre o caso brasileiro, é evidente que o déficit fiscal e a acumulação da dívida não eram sustentáveis. Mas a súbita reviravolta na confiança do mercado e na vontade dos investidores internacionais de emprestar ao Brasil foi explicada não por acontecimentos particulares ao Brasil, mas pelo contágio da crise russa. No caso do México em 1994, ao contrário, os acontecimentos políticos internos e o crescente déficit em conta corrente certamente explicaram o momento da crise, embora a intensidade do pânico - levando a uma severa recessão no México e ao ajuste excessivo da taxa de câmbio - só possam ser explicados em termos dos caprichos do mercado.

\section{QUE CONCLUSÕES TIRAR ACERCA DA ESCOLHA DO REGIME?}

Nenhum regime tem apenas vantagens ou desvantagens - sempre existem compensações. ${ }^{8}$ Além disso, as políticas que resultaram em crises não estavam necessa-

\footnotetext{
${ }^{7}$ Para uma excelente revisão de propostas de reforma realistas e irrealistas, ver Barry Eichengreen, Towards a New International Financial Architecture (Institute for International Economics, 1999).

${ }^{8}$ Para uma visão geral das questões aqui discutidas, e mais, ver Mussa e outros, Exchange Rate Regimes.
} 
riamente erradas, dado o conhecimento disponível aos tomadores de decisão no momento e dadas as expectativas razoáveis. Segue-se que simples recomendações, como "todas as taxas de câmbio devem flutuar" ou "todos os países em desenvolvimento devem instituir "currency boards", devem ser vistas com ceticismo. A visão atualmente mais em moda é a de que, em vista da alta mobilidade dos capitais internacionais, os FBARs não são mais factíveis ou desejáveis. ${ }^{9}$ De acordo com essa visão, a escolha está entre sistemas de taxa rigidamente fixada, como os "currency boards" ou as uniões monetárias, de um lado, e os regimes flutuantes, talvez com algum monitoramento, de outro. Jeffrey Frankel chama isso de "a hipótese do regime intermediário evanescente". ${ }^{10}$

Pode-se concluir que todos os regimes cambiais são factíveis quando os fundamentos são satisfatórios. Os problemas apenas se manifestam no comportamento da taxa de câmbio; eles não são causados pelo regime cambial. Mas tal conclusão seria muito extrema. A experiência, começando com o colapso do sistema de Bretton Woods e seguindo-se por muitos outros episódios - notadamente as crises do Leste da Ásia e os casos descritos neste livro - sugere que os FBARs são particularmente vulneráveis a crises. O problema reside em combinar um forte comprometimento a uma taxa fixa com a independência monetária e a alta mobilidade do capital. Isso não significa que os extremos - flutuação pura e regimes rigidamente fixados - são as únicas opções. ${ }^{11}$ Os FBARs, nos quais os ajustes são feitos rapidamente em resposta a mudanças nos fundamentos e a pressões do mercado, podem ser factíveis, mesmo se não forem ideais.

O centro do problema com o FBAR é o potencial para crises, causado pela especulação cambial, quando o ajuste na taxa de câmbio é relutante em resposta a mudanças nos fundamentos, inclusive mudanças nos fluxos de capital. Os Bancos Centrais inevitavelmente incorrem em perdas quando tentam em vão segurar uma taxa de câmbio que no final tem de ser depreciada, e os Ministros da Fazenda inevitavelmente perdem credibilidade. Mas uma variante modificada do regime FBAR ainda poderia ser factível. As taxas de câmbio precisam ser prontamente ajustadas, com ajustes automáticos através de crawling pegs anunciadas previamente quando a taxa de inflação de um país aumenta significativamente acima da taxa de seus parceiros e competidores comerciais. O ajuste não pode ser relutante. Isso pode ser descrito como um regime de paridade flexível. Além disso, pode haver

Ver também Jeffrey A. Frankel, No Single Currency Regime Is Right for All Countries or at All Times, Essays in International Finance 215 (International Finance Section, Princeton University, 1999).

${ }^{9}$ Ver Obstfeld e Rogoff, “The Mi age of Fixed Exchange Rates” e especialmente Barry Eichengreen, International Monetary Arrangements for the 21st Century (Brookings, 1994), este último sendo em geral considerado a fonte original dessa linha de pensamento. Esta visão - aplicada apenas às moedas dos principais países desenvolvidos - também é discutida em Corden, Economic Policy, Exchange Rates, and the International System, cap.16.

${ }^{10}$ Frankel, No Single Currency Regime.

${ }^{11}$ Para esta visão, exposta em profundidade, ver sobretudo Frankel, No Single Currency." 
uma taxa flutuante em torno da taxa central fixa ou indexada. Assim, um regime intermediário bastante próximo da flutuação monitorada, mas não exatamente um regime puro de taxa flutuante, pode ainda ser escolhido. ${ }^{12}$

Quanto aos regimes de taxa flutuante ou flexível, a evidência que temos até agora do México, do Brasil e do Chile (e também do Leste da Ásia) é de que as taxas flutuantes monitoradas, ou paridades muito flexíveis, podem funcionar muito bem - isto é, tais regimes não levam a uma instabilidade excessiva da taxa de câmbio, a não ser no período imediato da crise, quando está sendo feita a transição para o regime de taxa flutuante. Além disso, eles podem ser compatíveis com inflação relativamente baixa, vindo a disciplina necessária diretamente das políticas monetária e fiscal. Como mencionado acima, no caso do Brasil existe uma política monetária explícita de metas de inflação. Mas nem os países latino-americanos nem os do Leste da Ásia chegaram ainda a experimentar um episódio de altos e baixos do setor privado sob tais regimes. Mais, no caso do México e do Brasil, é simples mente muito cedo para ter certeza de que não haverá outro episódio de perda de disciplina fiscal e monetária.

Também é interessante observar a experiência australiana. A crise do Leste da Ásia levou a uma aguda deterioração das relações de troca na Austrália, mas, graças a uma taxa flutuante monitorada, o país sobreviveu sem um declínio significativo em sua taxa de crescimento. Não houve nenhuma tentativa de aumentar as taxas de juros para sustentar a taxa de câmbio. Essa experiência atua em defesa da flutuação, embora com algum monitoramento através da intervenção direta no mercado cambial. Um passado de políticas monetária e fiscal conservadoras foi crucial, como sempre acontecerá com os regimes de taxa flutuante.

Economias muito pequenas e abertas são claras candidatas à instituição de regimes de currency board ou a se tornarem parte de uniões monetárias. Isso decorre da teoria das áreas de moeda ideal e é uma proposição bem estabelecida. ${ }^{13} \mathrm{~A}$ questão mais importante e interessante é saber se um regime de âncora nominal com taxa fixa é adequado para economias maiores e menos abertas. Esses países, sobretudo Brasil, México e Chile, têm feito uso de sua taxa de câmbio como uma âncora nominal temporária. Se o país tem uma taxa de inflação muito alta e deseja embarcar num programa de estabilização radical que inclua a reforma da política fiscal, pode realmente ser o caso de se usar uma política cambial de âncora nominal como parte do pacote. Tais pacotes têm tido notável sucesso na redução drástica da inflação em alguns casos (sobretudo o Brasil depois de 1991 e o México depois de 1988).

Se o país estiver sujeito a graves choques exógenos, no entanto, ele não estará adequado a um regime de taxa permanentemente fixa. Não estará, portanto, ade-

\footnotetext{
12 John Williamson, The Crawling Band as an Exchange Rate Regime: Lessons from Chile, Colombia, and Israel (Institute for International Economics, 1996).

${ }^{13}$ A teoria das áreas de moeda ideal teve sua origem em Robert A. Mundell, "A Theory of Optimum Currency Areas", American Economic Review. vol. 51 (1961), pp. 657-65.
} 
quado, a um currency board. O caminho ideal seria fazer uma transição oportuna para um regime mais flexível - em outras palavras, mudar do método de âncora nominal para o método das metas reais. Se a mudança não for feita a tempo, uma crise cambial irá forçar essa transição, como aconteceu no México e no Brasil. O problema então é encontrar uma "estratégia de saída" adequada, ou seja, uma maneira graciosa e sem crises de sair de um FBAR para um regime de taxa flexível ou flutuante. ${ }^{14}$ Alternativamente, a mudança de método poderia ser descrita como fazer um a juste mais rápido dentro do esquema de um FBAR. Mas esse tipo de ajuste rápido e frequente é mais fácil na teoria do que na prática, em razão da síndrome do ajuste relutante da taxa de câmbio. E mais, se essa saída já for esperada pelo mercado (isto é, se houver " expectativas racionais”), pode ser inevitável uma especulação prévia contra a taxa da âncora nominal - especulação que levaria a uma crise. O melhor conselho é que, antes de mais nada, os países devem evitar chegar a uma situação de inflação alta - geralmente causada pela monetarização dos déficits fiscais - e essa é uma lição que a América Latina está aprendendo. Não haveria então nenhum a necessidade de usar a taxa de câmbio como uma âncora nominal temporária.

Resta a questão de saber se uma economia relativamente grande e não muito aberta deveria escolher um regime de currency board. Os analistas de políticas continuarão a acompanhar de perto o experimento de currency board da Argentina. Obviamente, ele tem alguns problemas - acima de tudo, o desemprego causado pela valorização real e inflexibilidade do mercado de trabalho. A Argentina também sofreu com alguns choques exógenos adversos, sobretudo com os desdobramentos das crises mexicana, asiática e russa, e da desvalorização brasileira. No entanto, os registros macroeconômicos da Argentina antes de 1991 eram tão ruins que o compromisso da nação com o novo regime não falhou. $\mathrm{O}$ fato de o Banco Central não poder agir como emprestador de último recurso para o sistema bancário no caso de uma crise bancária é um problema menor para a Argentina do que seria para muitos outros países, em virtude da alta proporção de bancos estrangeiros, capazes portanto de receber suporte financeiro do exterior. A Argentina não é uma economia pequena e não é particularmente aberta; seu comércio também não é pesadamente voltado para os Estados Unidos como é o do México, por exemplo, e seu mercado de trabalho não é particularmente flexível (à diferença do de Hong Kong, outro país com currency board). Desse modo, pelos critérios clássicos da teoria da área de moeda ideal, a Argentina não é um candidato óbvio para um regime de taxa rigidamente fixada. O critério preponderante aqui é a necessidade de uma âncora nominal em razão de uma história de falta de disciplina monetária e fiscal. A proposta mais recente no debate latino-americano sobre a taxa de câmbio é

\footnotetext{
${ }^{14}$ A questão da estratégia de saída é discutida em Barry Eichengreen, Paul Masson, Miguel Savastano, e Sunil Sharma, Transition Strategies and Nominal Anchors on the Road to Greater Exchange Rate Flexibility. Essays in International Finance 213 (International Finance Section, Princeton University, 1999)
} 
que esses países deveriam "dolarizar" ${ }^{15}$ Mesmo se a perspectiva de dolarização acabou se tornando ultimamente uma mania, sobretudo na Argentina, ela pode ainda ser uma opção sensata para alguns países, notadamente os menores. ${ }^{16} \mathrm{~A}$ dolarização oficial - para distingui-la da dolarização privada ou espontânea, que já aconteceu em grande medida em alguns países (Argentina e Rússia, por exemplo) - é um passo além do currency board. Desse modo, a comparação relevante é com a opção do currency board, dado que as importantes vantagens e desvantagens do regime de currency board e da dolarização são os mesmos.

A dolarização, assim como a adesão a uma união monetária, eliminaria completamente a possibilidade de especulação contra a moeda do país, que não mais existiria. Deve-se ter em mente, no entanto, que dois países com currency board, a Argentina e Hong Kong, sofreram especulação contra suas taxas de câmbio. Com a dolarização, as taxas de juros cairiam e um significativo elemento de incerteza para a economia ficaria reduzido. A possibilidade de desvalorização em caso de um choque grave - que continua existindo na presença de um currency board- ficaria assim descartada. Os governos perdem uma liberdade residual e ganham em credibilidade. É uma compensação conhecida. Há também uma perda de senhoriagem, que são os juros ganhos sobre as reservas cambiais mantidas como suporte da base monetária no caso de um currency board. Uma vez tomada a decisão de integrar completamente a economia com os Estados Unidos, e desde que objeções políticas ou simbólicas sejam superadas, essa pode ser uma opção real para alguns países.

Para concluir, com relação aos regimes cambiais na América Latina, o futuro é incerto. O México e o Brasil com suas taxas flutuantes, o Chile com sua paridade flexível e seu regime de ampla banda de flutuação, e a Argentina com seu currency board, todos parecem estar se saindo razoavelmente bem. Seu bem-estar atual sugere que muitos regimes são possíveis e podem ter sucesso, desde que não haja nenhum choque importante. Os mais vulneráveis são os FBARs com seus atrelamentos fortes mas não absolutamente invioláveis a uma taxa fixa ou a um a velocidade de indexação particular. Esse é o cenário aparente no momento atual, no início de 2000, embora não seja necessário que permaneça assim. Mas se a Argentina prosperar enquanto vários choques e a instabilidade dos mercados de capital fizerem sofrer países com taxas flutuantes, pode-se esperar que os regimes de currency board, ou talvez mesmo a dolarização, se tornem mais disseminados.

\footnotetext{
${ }^{15}$ Ver Guillermo A. Calvo, "Capital Markets and the Exchange Rate with Special Reference to the Dollarization Debate in Latin America”, University of Maryland (www.bsos.umd.edu/econ/ciecalvo. htm [Abril 2000]; e "The Pros and Cons of Dollarization", in World Economic Outlook (International Monetary Fund, Abril 2000), cap. 1. Para uma discussão crítica, ver Frankel, No Single Currency Regime.

${ }^{16}$ Em 2000 o Equador foi oficialmente dolarizado.
} 